\title{
Effect of temperature and relative humidity on the development times and survival of Synopsyllus fonquerniei and Xenopsylla cheopis, the flea vectors of plague in Madagascar
}

\author{
Katharina S. Kreppel ${ }^{1 *}$, Sandra Telfer ${ }^{2}$, Minoarisoa Rajerison ${ }^{3}$, Andy Morse ${ }^{4,5}$ and Matthew Baylis ${ }^{1,5}$
}

\begin{abstract}
Background: Plague, a zoonosis caused by Yersinia pestis, is found in Asia, the Americas but mainly in Africa, with the island of Madagascar reporting almost one third of human cases worldwide. In the highlands of Madagascar, plague is transmitted predominantly by two flea species which coexist on the island, but differ in their distribution. The endemic flea, Synopsyllus fonquerniei, dominates flea communities on rats caught outdoors, while the cosmopolitan flea, Xenopsylla cheopis, is found mostly on rats caught in houses. Additionally S. fonquerniei seems restricted to areas above $800 \mathrm{~m}$. Climatic constraints on the development of the two main vectors of plague could explain the differences in their distribution and the seasonal changes in their abundance. Here we present the first study on effects of temperature and relative humidity on the immature stages of both vector species.
\end{abstract}

Methods: We examined the two species' temperature and humidity requirements under experimental conditions at five different temperatures and two relative humidities. By employing multivariate and survival analysis we established the impact of temperature and relative humidity on development times and survival for both species. Using degree-day analysis we then predicted the average developmental threshold for larvae to reach pupation and for pupae to complete development under each treatment. This analysis was undertaken separately for the two relative humidities and for the two species.

Results: Development times and time to death differed significantly, with the endemic $S$. fonquerniei taking on average 1.79 times longer to complete development and having a shorter time to death than $X$. cheopis under adverse conditions with high temperature and low humidity. Temperature had a significant effect on the development times of flea larvae and pupae. While humidity did not affect the development times of either species, it did influence the time of death of $\mathrm{S}$. fonquerniei. Using degree-day analysis we estimated an average developmental threshold of $9^{\circ} \mathrm{C}$ for S. fonquerniei, and $12.5^{\circ} \mathrm{C}$ for $X$. cheopis.

(Continued on next page)

\footnotetext{
* Correspondence: Katharina.Kreppel@glasgow.ac.uk

${ }^{1}$ LUCINDA group, Institute of Infection and Global Health, Department of

Epidemiology and Population Health, University of Liverpool, Leahurst

Campus, Neston CH64 7TE, UK

Full list of author information is available at the end of the article
} 
(Continued from previous page)

Conclusions: While many vector-borne diseases are limited to warm, low-lying regions, plague in Madagascar is unusual in being most prevalent in the cool, highland regions of the country. Our results point towards the possibility that this is because the endemic flea vector, S. fonquerniei, is better adapted to cool temperatures than the exotic flea vector, $X$. cheopis. Future warming caused by climate change might reduce the area suitable for $S$. fonquerniei and may thus reduce the incidence of plague in Madagascar.

Keywords: Xenopsylla cheopis, Synopsyllus fonquerniei, Plague vector, Development time, Degree-days, Saturated salt solutions

\section{Background}

Plague, a vector-borne, highly virulent zoonotic disease is still present today in Africa, Asia and the Americas. It is caused by infection with the bacterium Yersinia pestis, with rodents and their fleas as its principal hosts. Transmission of bubonic plague to humans occurs via the bite of an infected flea and if left untreated, it triggers serious illness with up to $55 \%$ case fatality in human populations $[1,2]$. In many parts of the world climate is known to affect plague dynamics [3-6] and like many vector borne diseases, the primary mechanisms are thought to be driven by local variation in factors such as temperature and rainfall. Presently, Africa accounts for more than ninety percent of all human plague cases reported globally. Within African countries, the majority of cases are reported from Madagascar and the Democratic Republic of Congo [1]. With 482 notified cases in 2014, Madagascar has for many years been the country worst affected by plague, experiencing seasonal recrudescence between September and April [7].

Plague is endemic in the highland region of Madagascar, above $800 \mathrm{~m}$ of altitude. The reasons for such pronounced foci include unique host and vector dynamics, special climate features such as warm, wet austral summers and cool, dry winters as well as extreme poverty [8]. In Madagascar, the principal host appears to be the black rat, Rattus rattus [9], with two flea species primarily involved in plague transmission: Xenopsylla cheopis (X. cheopis), a cosmopolitan, exotic species, and Synopsyllus fonquerniei (S. fonquerniei), an endemic species. The two vector flea species coexist on the island, but occupy different niches, with $X$. cheopis found primarily on black rats within dwellings, while the endemic S. fonquerniei dominates the flea communities infesting rats living outdoors [10]. Below $800 \mathrm{~m}$ altitude S. fonquerniei appears to be absent $[8,11]$.

In the central highlands of Madagascar, both human plague incidence and the abundance of the two flea vector species show seasonal cycles. Most human cases of plague are reported during the warm rainy season from October to March [2, 12]. At least in urban areas, numbers of adult X. cheopis are low from April to December, whilst in rural areas numbers of adult $S$. fonquerniei increase during the cold dry season (from July onwards), peaking in September to January [13].

Like other ectoparasite species, flea distribution and abundance can be significantly affected by climatic variables. The immature stages of fleas develop in host burrows and are sensitive to air temperature and humidity, with effects on both development and survival times $[14,15]$. Thus, the regional and local differences in the spatial distribution of $X$. cheopis and S. fonquerniei within Madagascar, and the contrasting seasonal cycles may be driven by differences in climate susceptibility between the two species. The climate across Madagascar is described as unimodal tropical, with a hot rainy season from November to March and a cold dry season from April to October. To determine the temperature and relative humidity ranges for the experiment, information from micro-climate measurements inside burrows of the black rat (Rattus rattus) in the highlands of Madagascar was used. Previously published work by Sharif et al. on the development time of X. cheopis from India in 1949 in relation to temperature and humidity [16] was also considered to make informed decisions on the temperatures chosen for the experiment. Although some experimental data is available for $X$. cheopis, little is known about the biology of S. fonquerniei, and there is a critical need for information on the basic developmental constraints of the two flea vector species to provide further insight into plague epidemiology in Madagascar. Here we present the first study investigating the temperature and humidity needs of S. fonquerniei under experimental conditions, by examining larval and pupal development as well as survival. We provide original data on the effects of climate on the development and survival of the endemic $S$. fonquerniei and its counterpart X. cheopis.

\section{Methods}

\section{Rearing conditions}

Colonies of both vector species originated from adult fleas collected in 2001 from a total of 12 different highland regions of Madagascar. New specimens of both species from these regions were added every year until 2006. Since collection, they have been maintained in 
insectaria at the Medical Entomology unit, Institut Pasteur de Madagascar (IPM).

The fleas were reared in covered glass jars, $1 / 4$ filled with a 50:1 mixture of rice husk and dried beef blood for larval nutrition, at $27 \pm 2{ }^{\circ} \mathrm{C}$ and $70 \% \pm 5 \%$ relative humidity (RH). To obtain sufficient numbers of larvae for the experiment, recently fed, adult male and female fleas were transferred into glass jars containing $2 \mathrm{~g}$ of rice husk as a surface for oviposition. After $24 \mathrm{~h}$ the adults were carefully removed and the jars with the eggs were left to stand in the insectaria for 6 days. The jars were checked once a day until newly hatched larvae were detected; larvae were only collected once from each jar to ensure the same age of the specimens. In other flea species, the RH conditions under which the eggs are incubated do not affect the development time of larvae subsequently exposed to different conditions [14].

\section{Experimental set up}

Between 2008 and 2009, Easy Log data loggers (EL USB-2, Lascar Electronics) were used to record temperature and relative humidity inside rat-burrows $(n=56)$ during the wet and dry season in villages reporting plague. In the dry season recorded burrow temperatures ranged from 17-22 ${ }^{\circ} \mathrm{C}$ and $65-81 \%$ relative humidity while in the wet season burrow temperatures were between $23-28{ }^{\circ} \mathrm{C}$ and $84-94$ $\%$ relative humidity. According to this information experiments were undertaken using incubators (NUVE ES 120, UK and Binder KBF, Germany) at five temperatures $\left(18,21.5,25,28.5\right.$ and $\left.32{ }^{\circ} \mathrm{C}\right)$, each at two RHs, $80 \%$ and $90 \%$. Using a method described in detail by Winston and Bates [17] and widely used since [18, 19], the RHs were obtained by adding saturated salt solutions of ammonium sulphate, $\left(\mathrm{NH}_{4}\right) \mathrm{SO}_{4}$, and sodium carbonate, $\mathrm{NA}_{2} \mathrm{CO}_{3}$, to $1.5 \mathrm{~cm}$ depth within airtight plastic boxes.

With five temperatures and two RHs, there were ten experimental treatments for each flea species. $\mathrm{RH}$ and temperature readings were taken in each box $24 \mathrm{~h}$ before use, and intermittently during the experiment, with hygrometers $(433 \mathrm{MHz}$ Cable free Hygrometer, Oregon Scientific, UK) to ensure that the climatic conditions were maintained.

Newly hatched S. fonquerniei $(n=1,288)$ and $X$. cheopis $(n=750)$ larvae, up to $24 \mathrm{~h}$ old, were transferred onto halved ELISA-plates (NUNC MaxiSorp ${ }^{\text {Ts }}$ polystyrene 96 well), with one larva per well. Each well contained $5 \mathrm{mg}$ of larval rearing medium (powdered rodent diet, dried beef blood and dried yeast at a ratio of 20:3:1 respectively). As a higher mortality rate became apparent, more S. fonquerniei larvae were reared than $X$. cheopis. Plates were placed on stands in the airtight boxes within the incubators and covered with fine nylon mesh to prevent escape during the first two days when the larvae are most active.
Larval survival and cocoon formation (also referred to as pupation) were noted daily. The developmental growth progress of the larval stages of both species was recorded every second day by placing the transparent ELISA plate under a microscope lit from below. $\mathrm{Pu}$ pation indicated completion of the active larval stage. Larvae were observed until they either pupated or died, except for a small number which had still not pupated after twice the time taken by the majority of their counterparts; these individuals were assumed to have a developmental problem and, although still alive, they were excluded from the study population (2.74 \%).

After pupation, cocoons were individually transferred into $5 \mathrm{ml}$ Eppendorfs and sealed with fine nylon mesh to prevent the adult flea escaping, once hatched. Each cocoon was then subjected to the same conditions as the larva before pupation. In some cases, however, cocoons were attached to the well, and could not be removed without risk of damage. In these cases, the wells were sealed with perforated Parafilm and maintained as for those in Eppendorfs. Eppendorfs and plates with cocoons were shaken gently every day to help stimulate emergence [20]. Once emerged, the adults were immobilised using ice to enable species confirmation and sex identification.

\section{Statistical analysis \\ Flea development: time to pupation and time to emergence} The data were divided into two sets for analysis: larval development time to pupation (LDT) and pupal development time to emergence (PDT). These analyses were restricted, respectively, to larvae that pupated successfully (521/750 (69.5\%) of X. cheopis and 245/1288 (19.0\%) of $S$. fonquerniei), and to pupae that emerged as adults (258/521 (49.5\%) of X. cheopis and 77/245 (31.4 \%) of S. fonquerniei). Temperature was log-transformed. LDTs and PDTs were tested for normal distribution using an Anderson Darling test. Outliers greater than the mean \pm 2 SD were removed from the analysis. For each dataset, linear mixed effects models were first used to examine the effects of temperature and $\mathrm{RH}$ on development time of each species individually. There was a potential of nonindependence of samples, as the individual larvae and pupae of one plate were likely to be from the same batch of eggs. To account for possible non-independence, plate was included as a random effect in all models. Subsequently, models were developed for the data of both species combined, with species as a fixed effect, and two-way interaction terms between temperature, $\mathrm{RH}$ and species. The purpose of the combined model was to examine differences in the effects of $\mathrm{RH}$ and temperature between species. Due to heterogeneity of variance in LDTs and PDTs between temperature treatments, a fixed variance structure as a function of temperature was used by applying a weights argument. This accounted for the larger 
variance in development times at lower temperatures. Model selection was based on the Akaike information criterion (AIC) [21] and the principle of parsimony: only when the AIC was reduced by 2 or more was the inclusion of an additional variable considered an improvement to the model [22]. All statistical analysis was carried out using the nlme package [23] in R 3.1.2 for Windows [24].

\section{Mortality and time of death}

To investigate the effect of species, temperature and humidity on the timing of death, survival analysis [25] was applied to the dataset on larval development. Pupal survival was not studied, as the time of death within their cocoon could not be established. Analysis was based on a Cox proportional hazard model. Model selection was based on AIC values. Larvae without a recorded time of death (i.e., remained as larvae, or had successfully pupated by the end of the experiment) were right-censored. Survivorship over time was plotted as Kaplan Meier survival curves for each treatment and species.

\section{Degree-day analysis}

A widely used method, degree-day analysis, was chosen to determine the thermal units needed by larvae to reach pupation, and by pupae to complete development [26, 27]. This analysis was undertaken for each species at the two RHs separately. Development rate is the reciprocal of development time. As development rates plateaued at the highest temperature in both species, a regression line was fitted to the linear part of the observed data, thus omitting data at $32{ }^{\circ} \mathrm{C}$. The linear regression equation was extrapolated to the $\mathrm{x}$-intercept to estimate the lower developmental threshold-the temperature at which the development rate is zero and the development time would therefore be infinite. The reciprocal of the slope of the linear regression was then used to estimate the thermal constant (k-value) of each species [28]. The K-value defines the sum of thermal energy above the threshold required for $50 \%$ of the population to complete their development stage. The thermal constant is expressed in degree-days (DD).

\section{Results}

Analysis of the raw data revealed that more individuals of $X$. cheopis completed both development stages successfully and emerged as adults than the endemic $S$. fonquerniei. Sixty-nine percent of larval $X$. cheopis survived to pupation, and $34 \%$ to adulthood. By comparison, only $19 \%$ and $6 \%$ of $S$. fonquerniei larvae reached the pupal and adult stages respectively. The male: female ratio of the emerged $X$. cheopis was 1: 0.79; that of S. fonquerniei was 1:2.5.

\section{The effects of treatment on development time}

The distributions of LDT and PDT were not significantly different from normal. LDTs of $X$. cheopis were faster than S. fonquerniei at almost all temperatures, at both 80 \% (Fig. 1a) and 90 \% RH (Fig. 1b); the single exception was at $18{ }^{\circ} \mathrm{C}, 80 \% \mathrm{RH}$, where S. fonquerniei developed at a similar rate to $X$. cheopis. At both RHs, the difference between the species was smallest at $18{ }^{\circ} \mathrm{C}$. Pooling data for both RHs, likelihood ratio tests confirmed the LDTs were significantly different between species at every temperature (Fig. 1c).

Considering each species separately, LDT for both species was best explained by temperature combined with the random effect plate. In both cases, LDT was negatively associated with temperature (Table 1a). In each of the best single species models RH had no effect on LDT.

Considering both species together, the best model for LDT, on the basis of the smallest AIC, combined temperature, $\mathrm{RH}$, species and plate. In this model (Table 3a), the main effects for RH, temp and species, and the interactions of species and $\mathrm{RH}$, were all significant.

Patterns for PDT were broadly similar to LDT. Considering each species separately, PDT for both species was best explained by temperature combined with the random effect plate. In both cases, PDT was negatively associated with temperature (Table 1b). There was no effect of RH on PDT in either species.

Considering both species together, the best model for PDT again combined temperature, $\mathrm{RH}$, species and plate (Table 2). Two variables (temperature and species) were significant, as was the interaction between them (Table $3 \mathrm{~b}$ ), while RH was not.

\section{Survival analysis}

Overall the Kaplan Meier survivorship curves indicated that $S$. fonquerniei larvae showed a higher mortality and faster decline in survivorship than X. cheopis (Fig. 2). In addition, the curves indicated that at the lower three temperatures the survival for $S$. fonquerniei declined faster under both RHs than the survival of $X$. cheopis. This was also valid at $32{ }^{\circ} \mathrm{C}$ temperature under $80 \% \mathrm{RH}$, while at $28.5{ }^{\circ} \mathrm{C}$ for both RHs and at $32{ }^{\circ} \mathrm{C}$ with $90 \%$ $\mathrm{RH}$, survival declined in a similar pattern in both species. In the Cox Proportional Hazards model, time to death of $X$. cheopis was significantly influenced by $\mathrm{RH}$ only, with larvae tending to live longer at higher $\mathrm{RH}$ (Table 4; Fig. 2). The effect of temperature and the interaction between temperature and $\mathrm{RH}$ were not significant. For S. fonquerniei, however, both $\mathrm{RH}$ and the interaction of RH with temperature significantly influenced survival time, while the effect of temperature alone approached but did not reach significance. Considering the significant interaction, at higher temperatures larvae lived longer at $90 \%$ than $80 \% \mathrm{RH}$, but at lower temperatures there was little effect of RH (Fig. 2). The model for both species combined showed a significant effect of species $(\beta=-1.176,95 \%, P<0.0001$, approximate hazard 


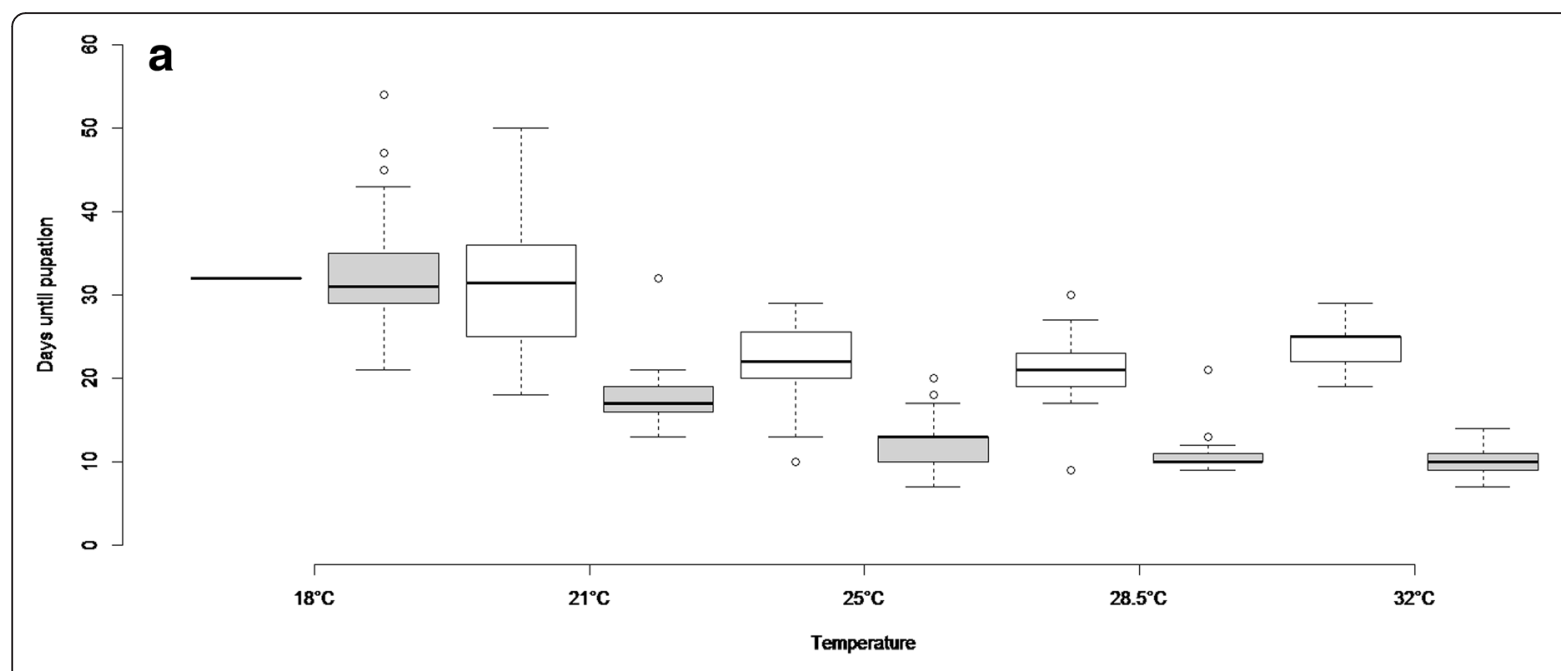

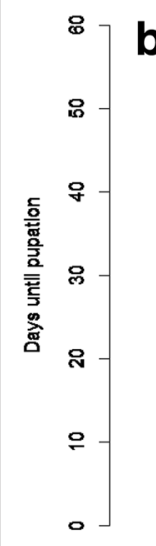

b<smiles>CC1CCCC1</smiles>
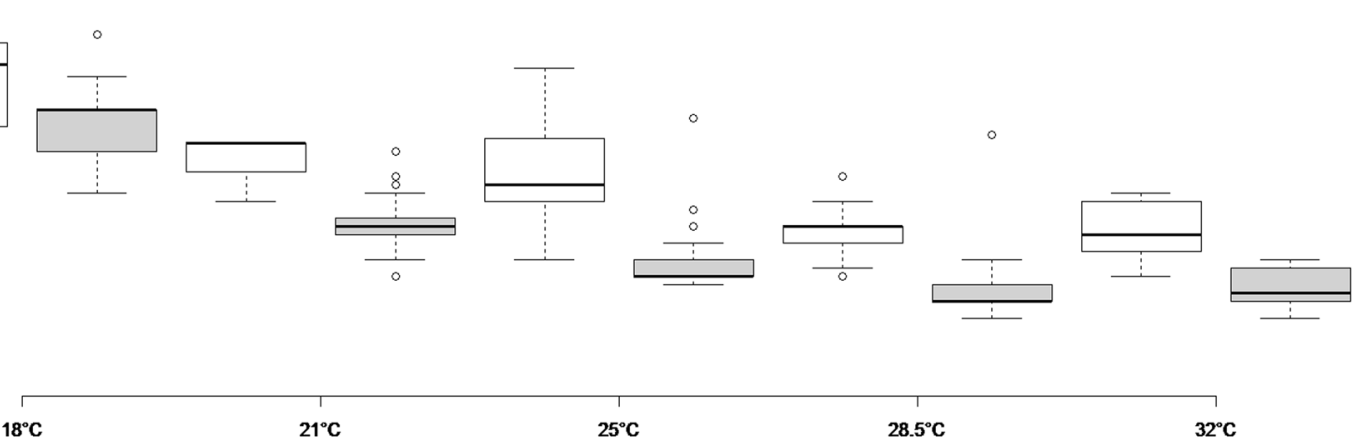

$21^{\circ} \mathrm{C}$

$25^{\circ} \mathrm{C}$

$28.5^{\circ} \mathrm{C}$

$32^{\circ} \mathrm{C}$

Temperature
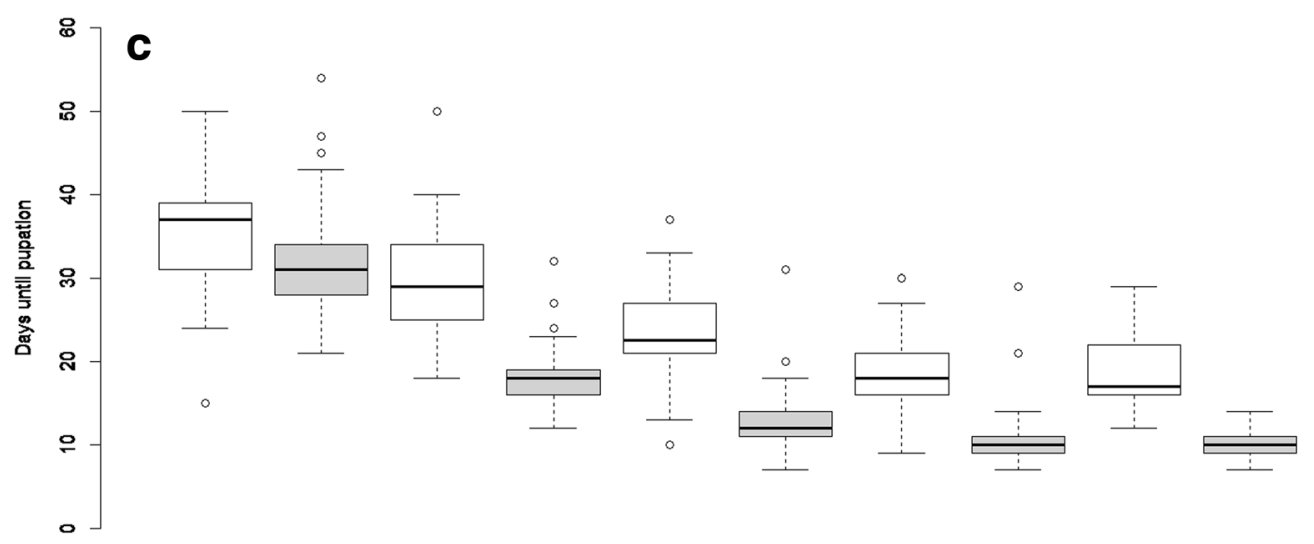

$$
18^{\circ} \mathrm{C}
$$

$21^{\circ} \mathrm{C}$

$$
25^{\circ} \mathrm{C}
$$

$28.5^{\circ} \mathrm{C}$

Temperature

Fig. 1 Distribution of larval development times (LDT) for S. fonquerniei (white) and X. cheopis (grey) at each temperature showing median values with $95 \%$ confidence intervals and first and third quartile. a $80 \%$ relative humidity b) $90 \%$ relative humidity c both humidities combined 
Table 1 Results of the best model for development time for each vector species separately. Model selection is based on $\triangle \mathrm{AIC}$ and parsimony. For both species variables include temperature (logtemperature) and PCR plate (plate)

a) Larval development time until pupation

Larval development time

Model: temperature (log), plate

$\begin{array}{lllll}\text { Species } & \text { Variable } & \text { coeff } & \text { SE } & p \text {-value } \\ \text { X. cheopis } & \text { Intercept } & 127.05 & 12.34 & <0.0001 \\ & \text { Logtemperature } & -79.67 & 8.90 & <0.0001 \\ \text { S. fonquerniei } & \text { Intercept } & 107.77 & 13.47 & <0.001 \\ & \text { Logtemperature } & -59.79 & 9.55 & <0.001\end{array}$

b) Pupal development time until emergence

Pupal development time

\begin{tabular}{lllll}
\multicolumn{5}{c}{ Model: temperature (log), plate } \\
Species & Variable & coeff & SE & $p$-value \\
X. cheopis & Intercept & 145.10 & 14.75 & $<0.0001$ \\
& Logtemperature & -88.82 & 10.58 & $<0.0001$ \\
S. fonquerniei & Intercept & 87.16 & 15.28 & $<0.0001$ \\
& Logtemperature & -49.47 & 10.68 & 0.0002 \\
\hline
\end{tabular}

ratio $=0.30, \mathrm{CI}=0.26-0.35)$ and a significant interaction between temperature and RH $(\beta=-0.045,95 \%, P=$ 0.0001 , approximate hazard ratio $=0.95, \mathrm{CI}=0.93-0.97$ ).

\section{Degree-day analysis}

Too few S. fonquerniei larvae developed at $18{ }^{\circ} \mathrm{C}$ to include them in this analysis. At $32{ }^{\circ} \mathrm{C}$ the development time plateaued and thus the data was also excluded. Using the remaining 3 temperatures, the developmental threshold (intercept of the regression line and the $\mathrm{x}$-axis) was 12.4 for $X$. cheopis and 9.3 for the endemic S. fonquerniei,

Table 2 Results of the model comparison for development time for both vector species combined for larval development time until pupation and for pupal development time until emergence

\begin{tabular}{|c|c|c|c|c|}
\hline \multicolumn{5}{|l|}{ X. cheopis and S. fonquerniei } \\
\hline \multirow[b]{2}{*}{ Model } & \multicolumn{2}{|c|}{ Larvae } & \multicolumn{2}{|c|}{ Pupae } \\
\hline & $\mathrm{df}$ & $\triangle \mathrm{AIC}$ & $\mathrm{df}$ & $\triangle \mathrm{AIC}$ \\
\hline $\mathrm{RH}+$ species, plate & 5 & 4381 & 5 & 2253 \\
\hline Logtemperature + species, plate & 5 & 4326 & 5 & 2210 \\
\hline Logtemperature $+\mathrm{RH}+$ species, plate & 6 & 4327 & 6 & 2208 \\
\hline Logtemperature | RH + species, plate & 7 & 4328 & 7 & 2208 \\
\hline RH | species + logtemperature, plate & 7 & $4322^{*}$ & 7 & 2208 \\
\hline Logtemperature | species, plate & 6 & 4327 & 6 & 2207 \\
\hline Logtemperature | species $+\mathrm{RH}$, plate & 7 & 4328 & 7 & $2205^{*}$ \\
\hline
\end{tabular}

Plus (+) corresponds to addition of variables while slash (|) corresponds to an interaction term between variables. Model selection is based on $\triangle \mathrm{AIC}$ and parsimony. The selected models are marked with an asterisk
Table 3 Results of the best model for development time for both vector species combined. Model selection is based on $\triangle \mathrm{AIC}$ and parsimony

a) For larval development time until pupation. Variables include humidity (RH \%), species, temperature (logtemperature) and PCR plate (plate).

$X$. cheopis and S. fonquerniei

LARVAE

Model: RH \% | species + temperature (log), plate

\begin{tabular}{|c|c|c|c|}
\hline Variable & coeff & SE & $p$-value \\
\hline intercept & 126.1829 & 20.989 & 0.0003 \\
\hline logtemperature & -71.898 & 14.813 & 0.0156 \\
\hline $\mathrm{RH} 90 \%$ & -3.4024 & 26.453 & 0.0242 \\
\hline species $X$. cheopis & -9.3341 & 22.636 & 0.0047 \\
\hline species X. cheopis | RH $90 \%$ & 3.37912 & 18.673 & 0.0200 \\
\hline \multicolumn{4}{|c|}{$\begin{array}{l}\text { b) For pupal development time until emergence. Variables include } \\
\text { species, temperature (logtemperature) and PCR plate (plate). }\end{array}$} \\
\hline \multicolumn{4}{|l|}{ X. cheopis and S. fonquerniei } \\
\hline \multicolumn{4}{|l|}{ PUPAE } \\
\hline \multicolumn{4}{|c|}{ Model: species | temperature (log) + RH \%, plate } \\
\hline Variable & coeff & SE & $p$-value \\
\hline intercept & 88.07774 & 19.35798 & \\
\hline logtemperature & -48.8746 & 13.57655 & 0.0009 \\
\hline species $X$. cheopis & 55.22215 & 22.76055 & 0.0159 \\
\hline $\mathrm{RH} 90 \%$ & -2.61925 & 1.378665 & 0.0649 \\
\hline logtemperature | species $X$. cheopis & -37.7761 & 15.97802 & 0.0187 \\
\hline
\end{tabular}

a difference of $3.1{ }^{\circ} \mathrm{C}$ (Table 5). The number of thermal units (k-value) needed by $50 \%$ of $X$. cheopis to complete larval and pupal development was 158 and 425 degree-days; while for S. fonquerniei it was 362 and 682 respectively.

\section{Discussion}

The study revealed longer larval and pupal development times with higher mortality rates for the endemic plague vector $S$. fonquerniei than $X$. cheopis. We also found a lower thermal developmental threshold for the former than for the latter. For both species temperature affected larval and pupal development times significantly, while the relative humidities included in this study did not. However, higher humidity reduced the risk of death at higher temperatures in S. fonquerniei.

\section{Larval and pupal development times}

$X$. cheopis, a widely distributed and well-studied flea species, was found to prefer higher temperatures in the laboratory. This is consistent with results from Sharif [16] and Mellanby [29]. There were differences between the species in the effects of temperature and humidity on development time. Temperature was the dominant factor, influencing the development rate of 

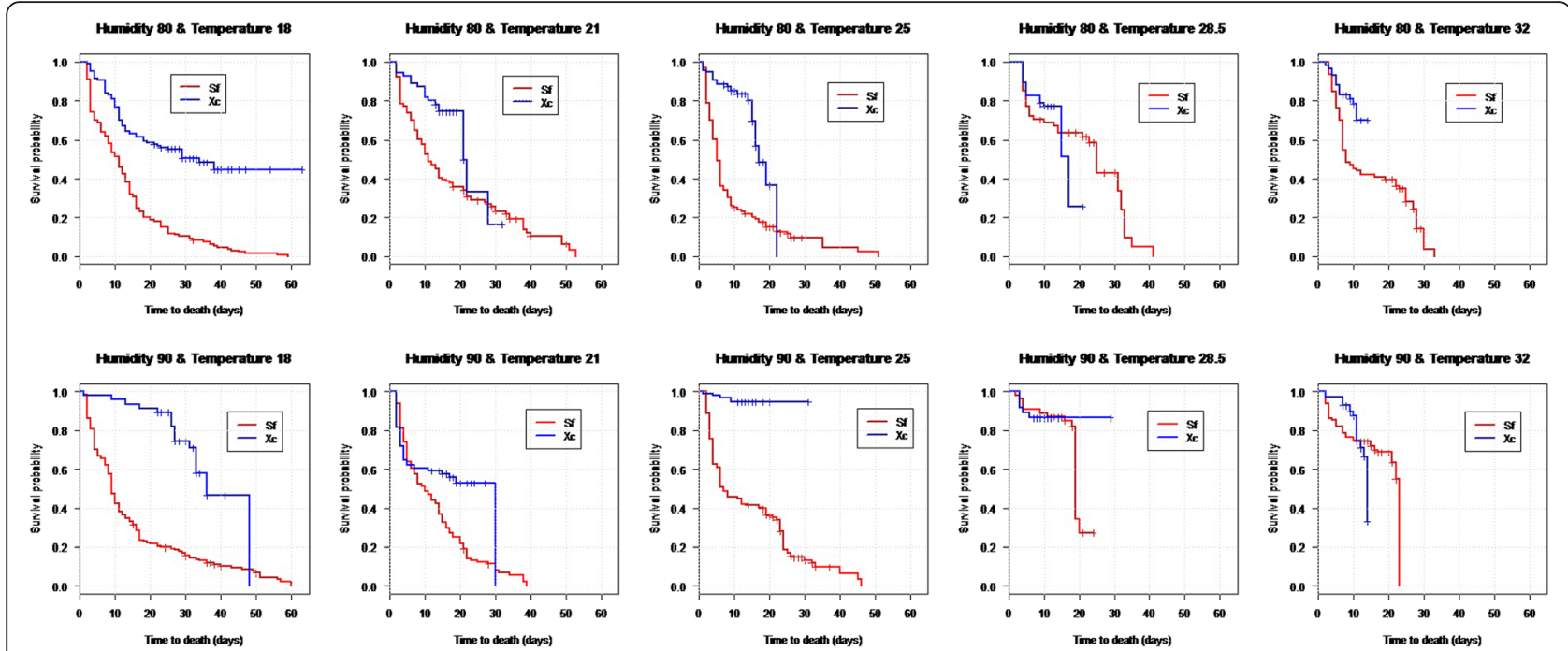

Fig. 2 Kaplan-Meier survival curves by species showing the survival probability for larvae across time at different humidities. The blue line shows the survival probability decline for $X$. cheopis while the red line shows the decline of the survival probability of $S$. fonquerniei

juvenile stages of both species. At higher temperature an accelerated development of larvae and pupae was observed in both species. Within the limitations of the study the effect of humidity was less prominent, with an effect only found on larval development when looking at both species together. The effect of only two humidities was tested and lower $\mathrm{RH}$ was associated with shorter development time for both species in combination with temperature. Larvae of $S$. fonquerniei developed much slower than the larvae of $X$. cheopis at all temperatures apart from the lowest $\left(18{ }^{\circ} \mathrm{C}\right)$. Pupal development time was similar for the two species, but, as with larvae, pupal development in $X$. cheopis was significantly more sensitive to declining temperatures.

\section{Mortality and time to death}

There were also differences between the species in the effects of temperature and humidity on survival time. Under laboratory conditions, larvae of $X$. cheopis survived longer at higher relative humidity, but no effect of temperature was detected. By contrast, survival times of larvae of $S$. fonquerniei were unaffected by relative humidity at low temperature, but at higher temperature they survived longer at higher relative humidity. Therefore, both species appear to survive longer at higher $\mathrm{RH}$, but this is only true for $S$. fonquerniei when at higher temperature. This is consistent with an effect of desiccation on survival of the larvae of S. fonquerniei. Air is capable of holding more moisture at higher temperatures, and warmer, dry air is therefore more able to desiccate insects than cooler, dry air. This effect of increased temperature as a cause of desiccation and hence mortality is partially offset at higher relative humidity, as the warm air's ability to desiccate is reduced.

\section{Degree-days}

Converting the development times to development rates, and plotting the rates against temperature, indicates that the temperature threshold for development is substantially lower for $S$. fonquerniei than $X$. cheopis. This is perhaps not unexpected; given the restricted distribution of S. fonquerniei's to the cool highlands of Madagascar, while $X$. cheopis is found throughout the island, and elsewhere. This may also be consistent with the presence

Table 4 Results from the Cox proportional hazard analysis on time to death for $X$. cheopis and S. fonquerniei

\begin{tabular}{llcccc}
\hline & Variable & Coefficient & $95 \% \mathrm{Cl}$ & P-value & Approx. hazard \\
\hline X. cheopis & Temperature & 0.01 & $0.97-1.04$ & 0.56 & 0.01 \\
& Relative humidity $90 \%$ & -0.347 & $0.52-0.94$ & 0.018 & 0.7 \\
& Temperature | Relative humidity & -0.016 & $0.92-1.04$ & 0.57 & 0.98 \\
S. fonquerniei & Temperature & -0.016 & $0.96-1.00$ & 0.062 & 0.98 \\
& Relative humidity 90\% & -0.271 & $0.67-0.86$ & $<0.0001$ & 0.76 \\
& Temperature | Relative humidity & -0.046 & $0.93-0.97$ & 0.0003 & 0.95 \\
\hline
\end{tabular}

Temperature was included as a continuous variable while relative humidity was considered dichotomous. Hazard values are estimated hazard values, calculated by taking the exponential of the coefficient 
Table $\mathbf{5}$ Thermal units needed by flea vector larvae of $X$. cheopis and $S$. fonquerniei to complete development to pupae at two humidities combined and for $80 \% \mathrm{RH}$ and $90 \% \mathrm{RH}$ separately

\begin{tabular}{llcll}
\hline & & $80 \%+90 \%$ & $80 \%$ & $90 \%$ \\
\hline X. cheopis & Threshold & 12.36 & 12.34 & 12.71 \\
& $\mathrm{R}^{2}$ - value & 0.77 & 0.75 & 0.76 \\
& $\mathrm{~K}$ - value & 158.15 & 158 & 155 \\
S. fonquerniei & Threshold & 9.26 & 9.14 & 8.57 \\
& $\mathrm{R}^{2}$ - value & 0.45 & 0.40 & 0.47 \\
& $\mathrm{~K}$ - value & 361.6 & 360.77 & 345 \\
\hline
\end{tabular}

of $S$. fonquerniei in outdoor rat burrows, while $X$. cheopis tends to be found only in burrows in houses which may be presumed to be warmer. Nevertheless, although $S$. fonquerniei is able to start developing at a lower temperature than $X$. cheopis, it requires a larger number of degree-days to achieve the same level of development (i.e. pupation).

\section{Implications for the field}

In terms of fleas, the endemic species, S. fonquerniei, is found predominantly in the cooler highland regions of Madagascar [12]. Our results may provide an explanation for this. The larvae of $X$. cheopis developed significantly faster than $S$. fonquerniei in all treatments except at the lowest temperature. Our results point towards the possibility that the endemic $S$. fonquerniei is better adapted to colder conditions found in the plague regions of Madagascar, while it may be outcompeted by $X$. cheopis in the warmer conditions that prevail in other parts of the island. This is supported by the degree-day analysis, estimating the developmental threshold of $S$. fonquerniei to be $3.1{ }^{\circ} \mathrm{C}$ lower than that of $X$. cheopis and thus giving the endemic $S$. fonquerniei an advantage in the colder highlands of Madagascar. However, due to the low number of larvae pupating at $18{ }^{\circ} \mathrm{C}$, particularly for $S$. fonquerniei, there was only limited power to estimate lower development rates and thresholds and compare them between species.

The highland plague focus in Madagascar may be due to interplay between the two vector-species present above $800 \mathrm{~m}$. S. fonquerniei's greater vectorial capacity [30] and lower developmental temperature threshold would enable it to sustain the plague cycle throughout the cold season where temperatures fall below $18{ }^{\circ} \mathrm{C}$ inside rat burrows until the population of $X$. cheopis is thriving again in the warm summer months.

Stenseth et al. [3] suggest that high flea abundance observed in a plague focus in Kazakhstan in spring is mediated by shorter development times, higher fecundity and increased survival due to favourable climatic conditions. Shorter development times and higher flea survival are also likely to lead to greater flea abundance in Madagascar; if so, our results suggest that greater flea abundances should occur in warmer, more humid environments, with the warmer temperatures favouring shorter development times and the higher humidity favouring survival. It is noteworthy, therefore, that the plague foci in Madagascar are largely restricted to the cool highland regions of the island [12], suggesting some disconnection between conditions favouring fleas and those favouring plague.

A frequently cited impact of climate change is that increasing temperatures will enable many vector-borne diseases to spread from warm, low-lying areas to higher, upland regions that were previously too cold. There is a considerable body of evidence that climate change has enabled malaria, for example, to spread into highland areas of East Africa and South America [31]. Plague in Madagascar, however, is unusual amongst vector-borne diseases in that it is endemic in the cool, highland areas of the country and largely absent (with the exception of the coastal town of Mahajanga) in the warm, low lying and coastal regions [32]. If this distribution is determined by non-climatic factors, such as human population density, then it is unlikely that climate change will have a significant future impact. Our study provides results that are, however, consistent with climate playing a major role in determining the distribution of plague in Madagascar; namely, the endemic flea vector S. fonquerniei, which has a high vectorial capacity for plague [30], survives better than the introduced flea species $X$. cheopis in the coolest, highland parts of the country. This is also supported by findings of the highest abundance of $S$. fonquerniei in the cool and dry season [2]. In that case, it may be that climate change will lead to a reduction in the incidence of plague in Madagascar as highland areas warm and become less suitable for S. fonquerniei and/or more suitable for $X$. cheopis.

The main aim of this study was to gather basic knowledge of the climatic constraints on the development of the flea $S$. fonquerniei, an important plague vector in Madagascar and a species endemic to that island. Previous studies on rodent fleas report species-specific effects of humidity and temperature on development times and adult survival $[15,16]$. This study presents a first attempt to quantify the effects of temperature and humidity on the developmental stages of $S$. fonquerniei and compare them to those of $X$. cheopis. The range of temperatures and humidities used in this study was narrow and further laboratory work would be necessary to determine both the upper and lower developmental threshold temperatures for both species.

\section{Conclusions}

The results of this study are consistent with $X$. cheopis' seasonal distribution patterns being determined by preimaginal development times [30]. 
Our results point towards the possibility that the endemic S. fonquerniei is better adapted to colder conditions found outdoors in the plague-endemic highlands. Our results suggest that a study with a wider range of temperatures and humidities and constant as well as fluctuating climate conditions would add valuable data and improve our understanding of the factors that determine the distribution of plague in Madagascar. In order to understand the vector-pathogen-host dynamics of plague an additional study evaluating the effects of different temperatures and RHs on plague transmission to mammal hosts by these flea species would be extremely valuable.

\section{Abbreviations \\ AIC: Akaike Information Criterion; DD: Degree-Days; IPM: Institut Pasteur de Madagascar; LDT: Larval Development Time; PDT: Pupal Development Time; RH: Relative Humidity; S. fonquerniei: Synopsyllus fonquerniei; $X$ cheopis: Xenopsylla cheopis.}

\section{Competing interests}

The authors declare that they have no competing interests.

\section{Authors' contributions}

ST and MB conceived the study; KK, MR, NE, AM and MB participated in its design and coordination. KK and ST carried out the laboratory experiment; $\mathrm{KK}, \mathrm{ST}$ and $\mathrm{MB}$ analysed the results; KK, ST and MB drafted the manuscript. All authors contributed to and approved the final manuscript.

\section{Acknowledgements}

We would like to thank Dr Lila Rahalison and Jocelyn Ratovonjato for their advice and help during the experiment. We are grateful to the staff of the Plague Unit and the Medical Entomology Unit at the Institut Pasteur de Madagascar, particularly Dr Nohal Elissa. Without their expertise this study would not have been possible. Sincere thanks to Mr Tojo Ramihangihajason for his technical assistance. We are indebted to the Institut Pasteur de Madagascar for an internal grant which facilitated additional laboratory research. Two Wellcome Trust fellowships supported ST during this work (081705 and 095171).

\section{Author details \\ 'LUCINDA group, Institute of Infection and Global Health, Department of Epidemiology and Population Health, University of Liverpool, Leahurst Campus, Neston CH64 7TE, UK. ${ }^{2}$ School of Biological Sciences, University of Aberdeen, Tillydrone Avenue, AB24 2TZ Aberdeen, Scotland, UK. ${ }^{3}$ Unité Peste - Institut Pasteur de Madagascar, BP 1274, Antananarivo 101, Madagascar. ${ }^{4}$ Department of Geography and Planning, School of Environmental Sciences, University of Liverpool, Liverpool, Merseyside L69 3GP, UK. ${ }^{5}$ Health Protection Research Unit in Emerging and Zoonotic Infection, University of Liverpool, Liverpool, Merseyside L69 3GP, UK.}

Received: 8 October 2015 Accepted: 6 February 2016

Published online: 11 February 2016

\section{References}

1. WHO. Human plague: review of regional morbidity and mortality 2004-2009, Wkly Epidemiol Rec. 2010;85:6.

2. Migliani R, Chanteau S, Rahalison L, Ratsitorahina M, Boutin JP, Ratsifasoamanana $L$, et al. Epidemiological trends for human plague in Madagascar during the second half of the 20th century: a survey of 20,900 notified cases. Trop Med Int Health. 2006;11(8):1228-37. doi:10.1111/j.1365-3156.2006.01677.x.

3. Stenseth N, Samia N, Viljugrein H, Kausrud K, Begon M, Davis S, et al. Plague dynamics are driven by climate variation. Proc Natl Acad Sci U S A. 2006;103(35):13110-5

4. Kreppel KS, Caminade C, Telfer S, Rajerison M, Rahalison L, Morse A, et al. A Non-Stationary Relationship between Global Climate Phenomena and
Human Plague Incidence in Madagascar. PLoS Negl Trop Dis. 2014;8(10): e3155. doi:10.1371/journal.pntd.0003155.

5. Schmid BV, Büntgen U, Easterday WR, Ginzler C, Walløe L, Bramanti B, et al. Climate-driven introduction of the Black Death and successive plaque reintroductions into Europe. Proc Natl Acad Sci. 2015;112(10):3020-5. doi:10.1073/pnas.1412887112.

6. Zhang Z, Li Z, Tao Y, Chen M, Wen X, Xu L, et al. Relationship between increase rate of human plague in China and global climate index as revealed by cross-spectral and cross-wavelet analyses. Integrative Zoology. 2007;2(3):144-53. doi:10.1111/j.1749-4877.2007.00061.x.

7. WHO. Weekly Epidemiological Record 2015; 20(90):217-52

8. Duplantier JM, Duchemin JB, Chanteau S, Carniel E. From the recent lessons of the Malagasy foci towards a global understanding of the factors involved in plague reemergence. Vet Res. 2005;36(3):437-53. doi:10.1051/vetres:2005007.

9. Duplantier JM, Catalan J, Orth A, Grolleau B, Britton-Davidian J. Systematics of the black rat in Madagascar: consequences for the transmission and distribution of plague. Biol J Linn Soc. 2003;78(3):335-41.

10. Klein JM, Uilenberg G. Données faunistiques et écologiques sur les puces de Madagascar (Siphonaptera). Cahiers ORSTOM Entomologie médicale. 1966:4(8):31-60

11. Soanandrasana Rahelinirina JMD. Jocelyn Ratovonjato, Olga Ramilijaona, Mamy Ratsimba, and Lila Rahalison. Study on the Movement of Rattus rattus and Evaluation of the Plague Dispersion in Madagascar. Vector-Borne and Zoonotic Diseases. 2010;10(1):77-84. doi:10.1089/vbz.2009.0019.

12. Chanteau $S$ et al., editors. Atlas de la peste a Madagascar. Paris, France: IRD Editions; 2006.

13. Klein JM. Données écologiques et biologiques sur Synopsyllus fonquerniei Wagner et Roubaud, 1932 (Siphonaptera), puce du rat péridomestique, dans la région de Tananarive. Cahiers ORSTOM Entomologie médicale. 1966;4(8):3-29

14. Krasnov BR, Khokhlova IS, Fielden LJ, Burdelova NV. Development rates of two Xenopsylla flea species in relation to air temperature and humidity. Med Vet Entomol. 2001:15(3):249-58.

15. Krasnov BR, Khokhlova IS, Fielden LJ, Burdelova NV. Effect of air temperature and humidity on the survival of pre-imaginal stages of two flea species (Siphonaptera : pulicidae). J Med Entomol. 2001;38(5):629-37.

16. Sharif M. Effects of Constant Temperature and Humidity on the Development of the Larvae and the Pupae of the Three Indian Species of Xenopsylla (Insecta: Siphonaptera). Philos Trans R Soc Lond B Biol Sci. 1949; 233(607):581-633. doi:10.2307/92397.

17. Winston PW, Bates DH. Saturated Solutions For the Control of Humidity in Biological Research. Ecology. 1960;41(1):232-7.

18. Arbogast RT, Carthon M. Humidity Response of Adult Oryzaephilus surinamensis (Coleoptera: Cucujidae). Environ Entomol. 1972;1(2):221-7.

19. Rockland L. Saturated salt solutions for static control of relative humidity between 5C and 40C". Anal Chem. 1960:32:1375-6.

20. Marshall AG. The sex ratio in ectoparasitic insects. Ecological Entomology. 1981:6(2):155-74

21. Akaike $\mathrm{H}$ et al. Information theory and an extension of the maximum likelihood principle. Proceedings of the 2nd international symposium on information theory. Budapest: Akademiai Kiado; 1973.

22. Johnson JB, Omland K. S. Model selection in ecology and evolution. Trends in Ecology\& Evolution. 2004;19:101-8.

23. Pinheiro J, Bates D, Debroy S, Sarkar D. NIme: Linear and nonlinear mixed effects models. 2007. R package version 3, 57.

24. Core-Team RD. R: A language and environment for statistical computing. Vienna, Austria: R Foundation for Statistical Computing; 2011.

25. Singh RMK. Survival analysis in clinical trials: Basics and must know areas. Perspect Clin Res. 2011;2:145-8

26. Campbell A, Frazer BD, Gilbert N. Gutierre.Ap, Mackauer M. Temperature requirements of some aphids and their parasites. J Appl Ecol. 1974; $11(2): 431-8$

27. Gu WD, Novak RJ. Statistical estimation of degree days of mosquito development under fluctuating temperatures in the field. J Vector Ecol. 2006:31(1):107-12

28. Arnold $\mathrm{CY}$. The determination and significance of the base temperature in a linear heat unit system. Proceedings of the American Society of Horticultural Sciences. 1959;74:430-45.

29. Mellanby K. The Influence of temperature and humidity on the pupation of Xenopsylla Cheopis. Bull Entomol Res. 1933;24:197-202. 
30. Duchemin J, Duplantier JM, Goodman SM, Ratovonjato J, Rahalison L, et al. La peste à Madagascar: faune endémique et foyers sylvatiques. Proceedings of the Conference: La peste : entre épidémies et sociétés, Marseille 23-26 juillet 2001. Firenze: Erga Edizioni Publishers; 2007.

31. Caminade C, Kovats S, Rocklov J, Tompkins AM, Morse AP, Colón-González FJ, et al. Impact of climate change on global malaria distribution. Proc Nat Acad Sci. 2014;111(9):3286-91. doi:10.1073/pnas.1302089111.

32. Andrianaivoarimanana V, Kreppel K, Elissa N, Duplantier J-M, Carniel E, Rajerison $\mathrm{M}$, et al. Understanding the Persistence of Plague Foci in Madagascar. PLoS Negl Trop Dis. 2013;7(11):e2382. doi:10.1371/journal.pntd.0002382

Submit your next manuscript to BioMed Central and we will help you at every step:

- We accept pre-submission inquiries

- Our selector tool helps you to find the most relevant journal

- We provide round the clock customer support

- Convenient online submission

- Thorough peer review

- Inclusion in PubMed and all major indexing services

- Maximum visibility for your research

Submit your manuscript at www.biomedcentral.com/submit
Biomed Central 